\title{
A COMPARISON OF ETIDOCAINE AND LIDOCAINE IN EPIDURAL ANALGESIA FOR SURGERY
}

\author{
A. Raksamani and G. Edelist
}

ETIDOCAINE HYDROCHLORIDE is a new potent long-acting local anaesthetic agent chemically related to lidocaine hydrochloride. We have previously compared these two drugs for epidural anaesthesia in obstetrics ${ }^{1}$ and indicated that the longer duration of action of etidocaine and its profound motor blockade might present advantages for surgical anaesthesia. This prompted us to undertake the present study.

\section{Method}

Sixty patients free of disease except for the condition being operated upon, ranging in age from 19 to 72, were included in the study. The females were of non-child bearing potential. All patients were scheduled for surgical procedures involving the lower abdomen, pelvic area, and lower limbs, and were free by history of sensitivity to local anaesthetic agents of the amide type. Informed consent was obtained and the experimental protocol was approved by the Human Research Committee of the University of Toronto.

Etidocaine 1 per cent without epinephrine or lidocaine 2 per cent without epinephrine in volumes of $15-30 \mathrm{ml}$ depending on the surgical procedure were injected into the epidural space with the patient in the lateral decubitus position. After injection the level of cutaneous analgesia was tested every minute with a 22-gauge needle until the upper limit of analgesia remained stable. The level was rechecked every 15 minutes thereafter until analgesia disappeared and a segment/time diagram of the area of analgesia was charted. The following parameters were recorded:

(1) Time to initial onset of sensory blockade.

(2) Time to complete sensory blockade which was defined as the time the highest level was achieved.

(3) Time to complete return of sensation defined as the time elapsed when no detectable sensory deficit to pin-prick could be determined.

(4) Degree of motor blockade. This was scored as $0,1,2$.

0 . Patient was able to flex knees and ankles completely.

1. Free ankle movement with impaired knee flexion.

2. No knee or ankle flexion.

(5) Duration to regression of two segments, defined as the time from complete onset and spread of sensory blockade to the time the sensory level decreased by two dermatomes on each side.

A. Raksamani, M.D. ${ }^{*}$ Resident in Anaesthesia. G. Edelist, M.D., F.R.C.P.(C), Professor, Dept. of Anaesthesia, University of Toronto, and Anaesthetist-in-Chief, Mount Sinai Hospital. Please direct correspondence to G. Edelist, M.D., Department of Anaesthesia, Mount Sinai Hospital, 600 University Avenue, Toronto, Ont. M5G 1X5

${ }^{\circ}$ Present address: Department of Anaesthesia, Siriraj Hospital, Bangkok, Thailand. 
TABLE I

Summary of Result of Evaluation \pm S.D.

\begin{tabular}{lcc}
\hline \hline & Etidocaine & Lidocaine \\
& $1 \% \%$ & $\mathbf{2 \%}$ \\
Initial sensory onset - Minutes & $4.68 \pm 1.84$ & $\mathbf{6} \pm 2.15$ \\
complete sensory block - Minutes & $12.18 \pm 4.16$ & $14 \pm 3.8$ \\
2 segment regression of sensory & $138.14 \pm 49.29$ & $80.40 \pm 26.51$ \\
block* - Minutes & & \\
complete return of sensory & $262.57 \pm 90.56$ & $146.06 \pm 34.65$ \\
function* - Minutes & & $102.86 \pm 47.90$ \\
complete return of motor & $257.84 \pm 98.79$ & $480 \pm 79.65$ \\
function* - Minutes & $237.50 \pm 34.49$ & $15.3 \pm 1.81$ \\
Dosage (mg)* & $15.75 \pm 2.38$ & $30 / 30$ \\
Numbers of dermatomes blocked & $25 / 30$ & \\
Satisfactory anaesthesia & &
\end{tabular}

*These means are significantly different $(p<0.01)$.

(6) Duration of motor blockade defined as the time from the loss of knee flexion to the time that the knees and ankles could be flexed completely.

\section{Results}

The observations made in this study are summarized in Table I. The initial onset of sensory block $4.68 \pm 1.84$ minutes for etidocaine as compared to lidocaine $6 \pm$ 2.15 minutes and the spread of cutaneous analgesia to its segmental limit $12.18 \pm$ 4.16 minutes for etidocaine as compared to $14 \pm 3.8$ minutes for lidocaine were not significantly different statistically. The duration of action of etidocaine was significantly longer both to two segment regression and to complete return of sensory function $(\mathrm{p}<0.01)$. The degree of motor blockade was very profound with etidocaine 1 per cent as compared to lidocaine 2 per cent and the duration of motor blockade was significantly longer $(p<0.01)$.

The quality of anaesthesia with etidocaine was satisfactory in only 25 of the 30 cases while it was satisfactory in all the lidocaine cases. With etidocaine three patients required supplementation with depressant drugs and two patients developed grand mal seizures. Because of the significance of this finding these two cases will be presented in detail in the discussion. The only other finding was transient local discomfort after the injection of 1 per cent etidocaine in eight cases. No significant hypotension or other signs of acute or chronic toxicity were noted.

\section{Discussion}

\section{Quality of Anaesthesia}

In a previous report ${ }^{1}$ we suggested that two of the properties of etidocaine that make it unacceptable for epidural obstetrical anaesthesia might make it highly acceptable for surgical anaesthesia, these being its long duration of action and its profound motor blockade. We have reaffirmed these two features in this study. However, we have noted one peculiarity which we have not observed with the other local anaesthetics commonly employed and that is the marked disparity between the motor and sensory block with etidocaine. In some patients the sensory 
block as measured by pin-prick is completely regressed while the patient is still unable to move his legs freely. This has created anxiety in some patients with regard to the paralysis, out of proportion to that seen with other local anaesthetics. The inability to move freely for long periods of time might also contribute to postoperative deep-vein thrombosis. We had three patients with levels of analgesia to pin-prick which we considered adequate for the surgical procedure and good muscle relaxation, who complained of pain to the extent that general anaesthetic supplement was required. Whether the high lipid solubility of this agent as compared to the others we use is conducive to more profound motor than sensory block is open to speculation, but we are unable to provide any theoretical explanation for this observed phenomenon.

The level of anaesthesia obtained with etidocaine 1 per cent in equivalent volumes was no different than that produced by lidocaine 2 per cent; that is $20 \mathrm{ml}$ of 1 per cent etidocaine will block the same number of segments as $20 \mathrm{ml}$ of 2 per cent lidocaine. This is in agreement with the work of Bromage. ${ }^{2}$ Therefore we might suggest that the therapeutic ratio of etidocaine to lidocaine for epidural analgesia for surgery is two to one.

\section{Toxicity}

The toxicity of etidocaine has been extensively studied. ${ }^{3-5}$ Adams et al. concluded that etidocaine was four times as toxic and four times as potent as lidocaine intravenously while it was only twice as toxic subcutaneously. Bromage suggests etidocaine is twice as potent and twice as toxic as lidocaine. Several large series reporting the use of etidocaine have been published which indicate a very low incidence of toxic reactions. ${ }^{78}$ However, Bromage ${ }^{6}$ suggested and the work of Scott ${ }^{5}$ seems to confirm that the toxic reaction to an inadvertent intravenous injection of etidocaine might be more severe than that to an equipotent dose of lidocaine. In our series of 30 cases we had two patients with grand mal seizures occurring before the full dose of the drug was injected, certainly suggesting an intravenous injection.

\section{Case 1}

This was a 34-year-old black female scheduled for post-partum tubal ligation. She was completely free of disease by history and physical examination. The epidural block was performed at L3-4 in the left lateral decubitus position using a 16gauge Touhy needle. The epidural space was identified easily by the hanging drop technique. No blood was noted in the needle and no paraesthesia was elicited. After $15 \mathrm{ml}$ of etidocaine 1 per cent had been injected slowly the patient lost consciousness and began to convulse. The injection was stopped; the patient was given 100 per cent oxygen to breathe, and the trachea was intubated after thiopentone $125 \mathrm{mg}$ and succinylcholine $80 \mathrm{mg}$ had been given. There was no sign of cardiovascular deterioration. Blood pressure and pulse were well maintained. The resuscitation was successful. No sign of sensory or motor block appeared and none could be elicited 45 minutes later when the patient was fully conscious and co-operative. There were no permanent sequelae.

\section{Case 2}

This was a 30-year-old black female for a post-partum tubal ligation who was 
completely free of disease by history and physical examination. The procedure was identical to that in Case 1 with no blood or paraesthesia noted and no difficulty with the procedure. After $17 \mathrm{ml}$ of etidocaine 1 per cent the patient lost consciousness and convulsed. She was resuscitated in a fashion identical to Case 1. Again 45 minutes later no sign of sensory or motor block was apparent and there were no subsequent untoward sequelae.

These two cases had several similarities. Both patients were post-partum less than 48 hours and were scheduled for tubal ligation. There was no evidence during the procedure that a blood vessel was entered and yet the rapid onset of convulsion after $15-17 \mathrm{ml}$ of injectate would leave little doubt that intravenous injection took place, particularly since no signs of epidural block occurred.

It is interesting that these two cases as well as that described in detail by Bromage $^{\mathbf{6}}$ occurred in young females in the peri-delivery period. At this time the epidural veins are quite distended and inadvertent intravenous injection is certainly a greater possibility.

In our hospital approximately 1,000 epidural anaesthetics for surgery and 3,000 for obstetrics are given annually and have been for the past twenty years. The incidence of toxic convulsions is .063 per cent. ${ }^{9}$ To see two cases in one week after the institution of a new agent is certainly very unusual and, since our technique did not change, we feel that the probability is great that etidocaine is more toxic upon inadvertent intravenous injection than the other commonly employed local anaesthetics. This is particularly true if the injection is fast, as shown by Scott." Another minor clinical problem was the incidence of pain on injection of etidocaine. This pain was mild but none-the-less did occur and has been observed by others who suggested that it was due to the low $\mathrm{pH}(4.37)$ of the solution. ${ }^{6}$

\section{SUMMARY}

Etidocaine 1 per cent has been compared with lidocaine 2 per cent for epidural anaesthesia for surgery. Etidocaine produced a block which was characteristically longer, with a more profound motor component than lidocaine. The quality of anaesthesia was not as satisfactory with etidocaine and the danger of inadvertent intravenous injection was underlined.

\section{RÉSUMÉ}

L'étidocaïne à 1 pour cent employée en péridurale pour la chirurgie a été comparée à la lidocaine à 2 pour cent. Le bloc produit par l'étidocaine est plus long et sa composante motrice est plus profonde que celle obtenue avec la lidocaïne. L'anesthésie obtenue est cependant moins satisfaisante avec l'étidocaine.

Les auteurs soulignent la toxicité relative plus grande de cet agent et les dangers de son administration intra-veineuse accidentelle.

\section{REFERENCES}

1. Edelist, G. \& Perera, E. Comparison of etidocaine and lidocaine for obstetrical analgesia. Canad. Anaesth. Soc. J. 23: 459-464 (1976). 
2. Bromage, P.R., O'Beirn, P., \& Dunford, L.A. Etidocaine: a clinical evaluation for regional analgesia in surgery. Canad. Anaesth. Soc. J. $21: 523-534$ (1974).

3. Adams, H.J., Kronbeng, G.H., \& Takman, B.H. Local anaesthetic activity and acute toxicity of ( \pm )-2-(N-Ethylpropylamino)-2', $6^{\prime}$-butyroxylidide, a new long-acting agent. J. Pharm. Sci., 61: 1829-1831 (1972).

4. Munson, E.S., Tucker, W.K., Ausinsch, B., \& Malagod, M.H. Etidocaine, bupivicaine, and lidocaine seizure thresholds in monkeys. Anesthesiology 42: 471-478 (1975).

5. ScotT, D.B. Evaluation of the toxicity of local anaesthetic agents in man. Brit. J. Anaesth. 47: 56-61 (1975).

6. Bromage, P.R., Datta, S., \& Dunford, L.A. Etidocaine: an evaluation in epidural analgesia for obstetrics. Canad. Anaesth. Soc. J. 21 : 535-545 (1974).

7. Bridenbaugh, P.O., Tucker, G.T., Moore, D.C., Bridenbaugh, L.D, \& Thompson, G.E. Etidocaine: clinical evaluation for intercostal nerve block and lumber epidural block. Anaesth. Analg. (Cleve) 52: 407-413 (1973).

8. Lund, P.C., Cwik, J.C., \& Pagdanganan, R.T. Etidocaine - a new long-acting local anaesthetic agent: a clinical evaluation. Anaesth. \& Analg. (Cleve) 52: 482-493 (1973).

9. Hellimans, K. Epidural anaesthesia in obstetrics: a second look at 26,127 cases. Canad. Anaesth. Soc. J. 12: 398-404 (1965). 